Monthly incidence of significant pulmonary thromboembolism (PTE) at Queen Mary Hospital, Hong Kong, 1987-1992

\begin{tabular}{|c|c|c|c|c|c|c|c|c|c|c|c|c|}
\hline & fan & $F e b$ & Mar & $A p r$ & May & fun & ful & Aug & Sep & $O c t$ & Nov & Dec \\
\hline No. of necropsies & 310 & 259 & 289 & 277 & 260 & 287 & 338 & 286 & 274 & 267 & 288 & 311 \\
\hline $\begin{array}{l}\text { No. of cases of significant PTE } \\
\text { Significant PTE (\% of total necropsies) }\end{array}$ & $\begin{array}{r}14 \\
4 \cdot 5\end{array}$ & $\begin{array}{c}14 \\
5 \cdot 4\end{array}$ & $\begin{array}{l}16 \\
5 \cdot 5\end{array}$ & $\stackrel{11}{4 \cdot 0}$ & $\begin{array}{l}12 \\
4 \cdot 6\end{array}$ & $\begin{array}{l}6 \\
2 \cdot 1\end{array}$ & $\begin{array}{l}7 \\
2 \cdot 1\end{array}$ & $\begin{array}{c}13 \\
4 \cdot 5\end{array}$ & $\begin{array}{l}11 \\
4 \cdot 0\end{array}$ & $\begin{array}{c}14 \\
5 \cdot 2\end{array}$ & $\begin{array}{l}7 \\
2 \cdot 4\end{array}$ & $\begin{array}{l}5 \\
1 \cdot 6\end{array}$ \\
\hline
\end{tabular}

of the year, no significant differences could be found. When the individual seasons were compared, the rate of pulmonary thromboembolism in summer (26/911) was lower than that in spring $(39 / 826), p<0.05$. When individual months were compared with the rest of the year, a significant difference was found only for December, where the rate was lower ( $p=0.05$ with Yates's correction). When the rates in two consecutive months were compared with those of the rest of the year, the troughs

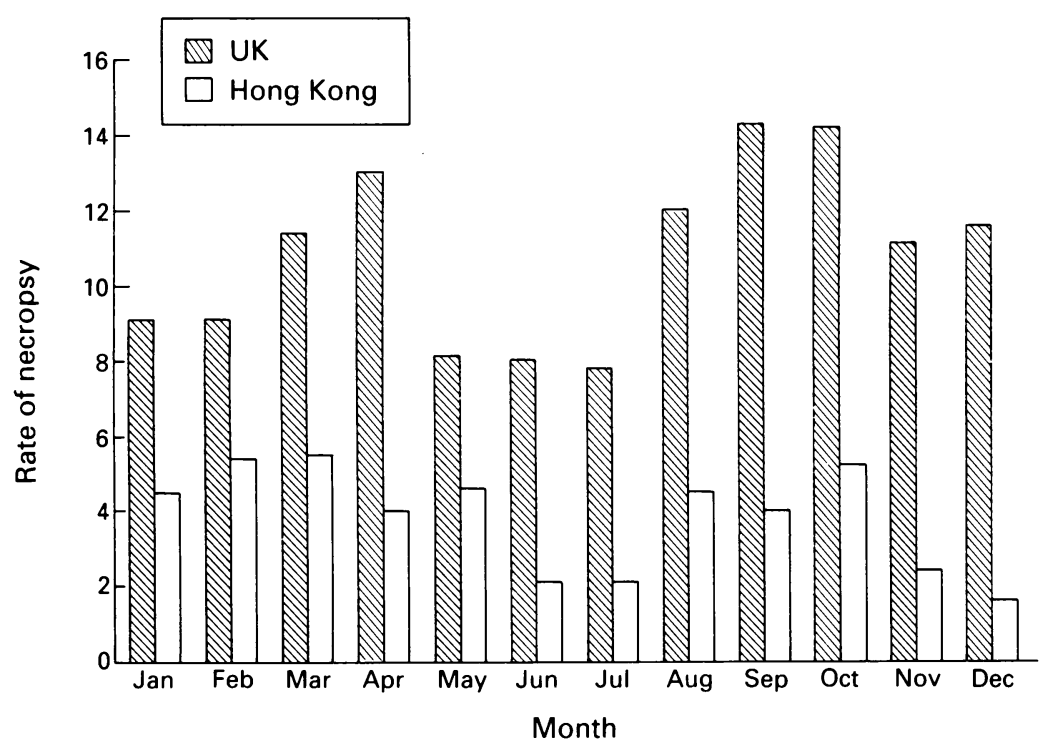

Monthly variation in the rates of necropsies with significant pulmonary thromboembolism (Hong Kong) or massive pulmonary embolism (UK). in both summer (June and July) and winter (November and December) had significantly lower rates $(\mathrm{p}<0.02$ for each period).

\section{Discussion}

The main feature of the pattern of seasonal variation in Hong Kong is the presence of two troughs in early summer and early winter. The main feature of the Birmingham report is the presence of two peaks in spring and autumn. In fact the two graphs show many similarities, and this pattern of variation of pulmonary thromboembolism is similar throughout the subtropical and the temperate regions. ${ }^{14}$ The postulations cited in the Birmingham report to explain the effect of weather on pulmonary embolism do not seem to hold for Hong Kong. The temperature in Hong Kong is moderate. There is very little variation and no extremes. Activities are not limited in any way by the weather. ${ }^{14}$ The true reasons for this seasonal variation in the incidence of pulmonary thromboembolism in Hong Kong, as for the United Kingdom, remains unknown.

1 Green J, Edwards C. Seasonal variation in the necropsy incidence of massive pulmonary embolism. $\mathcal{f}$ Clin Pathol 1994;47:58-60.

2 Chau KY, Yuen ST, Ng THK, Ng WF. An autopsy study of pulmonary thromboembolism in Hong Kong Chinese. Pathology 1991;23:181-4.

3 Bergqvist D, Lindblad B. A 30-year survey of pulmonary embolism verified at autopsy: an analysis of 1274 surgical patients. Br 7 Surg 1985;72:105-8.

4 Scharnoff JC, Rosenberg M, Mistica BA. Seasonal variation in fatal thromboembolism and its high incidence in the surgical patient. Surg Gynecol Obstet 1963;116:11-4.

\author{
Hospital Comarcal \\ del Noroeste, \\ Caravaca \\ de la Cruz, \\ 30400 Murcia, \\ Spain: \\ Internal Medicine \\ G F Alguacil-Garcia \\ M Martinez-Albadalejo \\ B Gonzalez-Pina \\ $M$ de Paco-Moya
}

\section{Pathology Service}

J Moreno-Requena

Gastroenterology Unit H Hallal-Hachem

Correspondence to: Dr G F Alguacil-Garcia Gran Via $126^{\circ}-\mathrm{B}$, Caravaca de la Crux, 30400 Murcia, Spain.

Accepted for publication 18 July 1994

\title{
Idiopathic granulomatous vasculitis: response to immunosuppressive therapy
}

G F Alguacil-Garcia, J Moreno-Requena, M Martinez-Albadalejo, H Hallal-Hachem, B Gonzalez-Pina, M de Paco-Moya

\section{Abstract}

A case of idiophatic granulomatous vasculitis (disseminated visceral giant cell arteritis) is described in an old woman, the seventh case of this rare disorder reported to date. The main organ affected was the liver and, to our knowledge, this is the first patient to be diagnosed while still alive and the only case to have received medical treatment. It is also the first time
\end{abstract}

that muscular involvement has been documented in this condition. Cyclophosphamide treatment resulted in disappearance of symptoms and increase in weight. The patient died of an unrelated condition.

(f Clin Pathol 1995;48:579-582)

Keywords: Visceral giant cell arteritis, cyclophosphamide. 


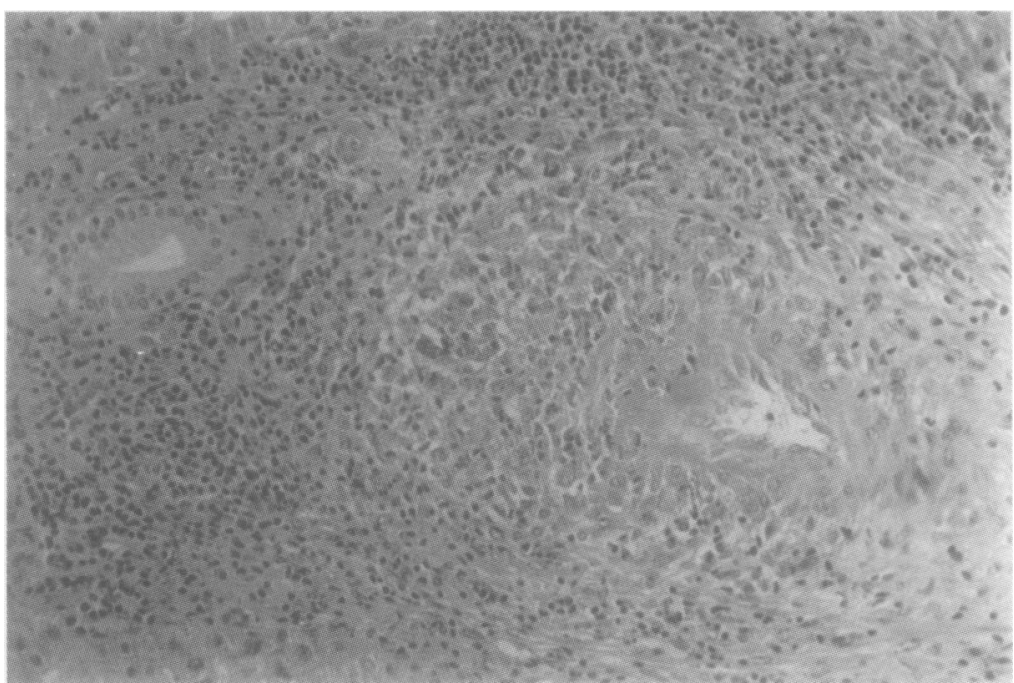

Figure 1 Granulomatous vasculitis of the liver. Acute and chronic inflammatory infiltrate of lymphocytes and neutrophils in small and medium size hepatic arteries. Focal fibrinoid necrosis and narrowing of vascular lumen. Haematoxylin and eosin, $\times 200$.
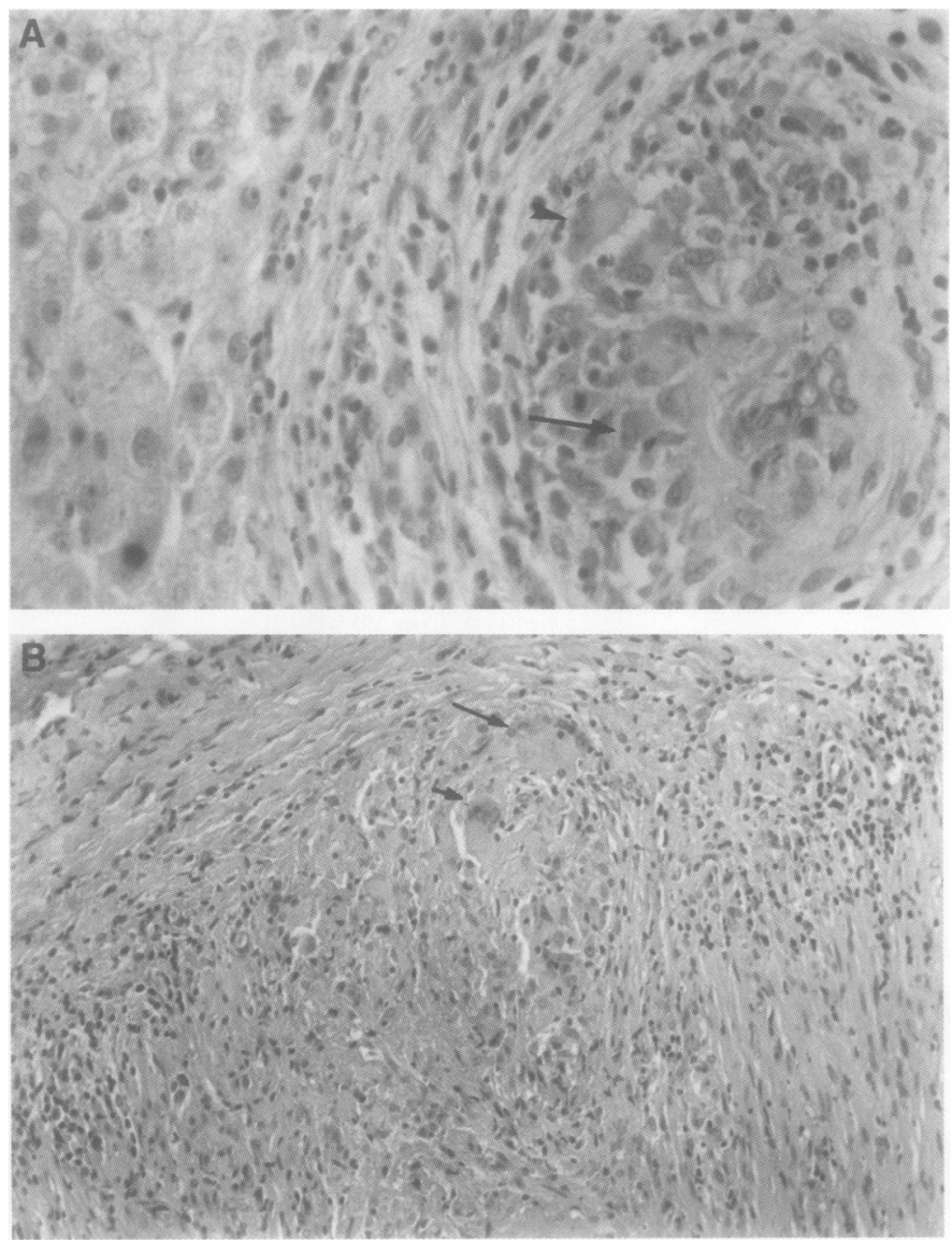

Figure 2 Granulomatous vasculitis of the liver. (A) Hepatic portal artery showing perivascular granuloma, peripheric lymphocytic infiltrate, histiocytes (long arrow), and giant cells (short arrow). Haematoxylin and eosin, $\times 325$. (B) Granulomatous lesion in giant cells (short arrow). Haematoxylin and eosin, $\times 325$. (B) Granulomatous lesion in
the wall of a medium sized hepatic artery, with presence of several multinucleated giant cells of Langhans type (arrows). Haematoxylin and eosin, $\times 200$.

Within the heterogeneous group of systemic vasculitides, there are some in which the most distinguishing histological characteristic is the existence of granulomatous lesions in the vascular wall. Though the most representative entities of this group are the granulomatous lung vasculitides (Wegener granulomatosis and Churg-Strauss disease), there are other rare conditions such as granulomatous vasculitis of the central nervous system, temporal arteritis, and some cases of vasculitis associated with the use of drugs which show similar histological lesions. ${ }^{12}$ In 1973 Lie described the necropsy findings in four patients who presented with granulomatous arteritis and giant cells in the small and medium sized vessels of several extracraneal organs. He considered that these patients had a new illness, closely related to temporal (giant cell) arteritis, which he called "disseminated visceral arteritis of giant cells". Two further cases were subsequently described (also in necropsies), ${ }^{4}$ and the condition was renamed "idiopatic granulomatous vasculitis". 4

In this paper we describe the seventh case of this rare disorder so far reported, and document the clinical response to the immunosuppressive therapy in this, the only patient with the illness who has been diagnosed while still alive and given medical treatment.

\section{Case report}

A 76 year old white woman with non-insulindependent diabetes mellitus, who had been treated with irregular doses of tolbutamide for two years, arrived at our emergency ward because of asthenia, anorexia, fever, ankle oedema, diffuse non-specific abdominal pain, and marked deterioration in her general condition. On physical examination cachexia, skin pallor, hepatomegaly, and moderate malleolar oedema was observed; there were no cutaneous lesions, palpable lymphadenopathy, signs of neuropathy, or other physical abnormalities on examination except for weakness and mild general muscular atrophy. Among the laboratory tests, the following results were found: packed cell volume $30 \%$, white cell count $6.9 \times 10^{9}$ cells $/ 1$ (neutrophils $77 \%$, lymphocytes $21 \%$, bands $2 \%$ ), platelet count $157 \times 10^{9} / 1, \mathrm{MCV} 92 \mathrm{fl}$, blood glucose $26 \mathrm{mmol} / \mathrm{l}$, alkaline phosphatase $440 \mathrm{U} / \mathrm{l}$, gammaglutamyl transferase $86 \mathrm{U} / \mathrm{l}$, serum iron $6 \mu \mathrm{mol} / \mathrm{l}$, serum ferritin $40 \mu \mathrm{g} / \mathrm{l}$, plasma creatinine $98 \mu \mathrm{mol} / 1$; aspartate transaminase, alanine transaminase, sodium, potassium, calcium, chloride, bilirubin, and uric acid showed normal plasma values. Total protein concentration was $56 \mathrm{~g} / 1$ (albumin $24 \mathrm{~g} / 1$, $\alpha 1$ globulin $3 \mathrm{~g} / \mathrm{l}, \alpha 2$ globulin $7 \mathrm{~g} / 1, \beta$ globulin $9 \mathrm{~g} / 1, \gamma$ globulin $13 \mathrm{~g} / \mathrm{l})$. HBsAg and rapid plasma reagin test was negative. Antinuclear antibodies were not found. Prothrombin time and partial thromboplastin time were normal. Urine results were as follows: protein $0.15 \mathrm{~g} /$ $24 \mathrm{~h}$, glucose $>20 \mathrm{~g} / \mathrm{l}, 10-15$ white cells and 2-3 red cells per high power field without granular or red cell casts, and Ziehl staining was negative. ECG showed non-specific ST segment and $T$ wave abnormalities and chest radiography was normal. An ultrasonographic examination of the abdomen showed mild homogeneous hepatomegaly and abdominal computed tomography (CT) revealed doubtful enlargement of the head of the pancreas. Barium examination of the colon, oesophagus, stomach, and duodenum showed no 
abnormalities. On suspicion of a neoplasm in the head of the pancreas, a laparotomy was done, but this did not confirm the findings of the abdominal CT scan. A wedge biopsy of the hepatic parenchyma was performed and a peripancreatic lymphatic ganglion and a small supernumerary spleen were removed. Histopathological examination of the lymphatic ganglion was normal, but both in the hepatic parenchyma and in the supernumerary spleen many foci of granulomatous vasculitis were seen involving several small and medium sized arteries, with focal lesions of fibrinoid necrosis, severe endarteritis, and acute and chronic periarteritis (fig 1). In places these lesions progressed to granulomas destroying the vascular wall (fig 2A and B), and containing multinucleated giant cells of the Langhans type (fig $2 \mathrm{~A}$ and B). Extravascular intralobular granulomas were also observed in the liver. Left temporal artery biopsy showed only arteriosclerotic changes. Right deltoid muscle biopsy showed endarteritis and periarteritis with no sign of fibrinoid necrosis, together with perivascular inflammatory infiltration. These findings were compatible with vasculitis of non-specific character.

Since the patient's condition continued to deteriorate, with anorexia, loss of weight, and elevation of serum alkaline phosphatase, it was decided to begin treatment with cyclophosphamide, $100 \mathrm{mg} /$ day for two weeks and then $50 \mathrm{mg} /$ day. The initial tolerance was excellent and she was discharged from hospital. Two months later her symptoms had disappeared, her weight had increased by $3 \mathrm{~kg}$, the packed cell volume was $34 \%$, and the alkaline phosphatase was $112 \mathrm{U} / \mathrm{l}$. The patient did not attend for follow up and we could not contact her.

Two and half years later, she came again to our emergency ward with anorexia, asthenia, arthralgia and itching which had started a month previously; she was still taking cyclophosphamide and a moderate pancytopenia was evident (packed cell volume $25 \%$, white cell count $2.9 \times 10^{9} / 1$, platelet count $65 \times 10^{9} / 1$ ). Creatinine, uric acid, alkaline phosphatase, aspartate transaminase, alanine transaminase, lactate dehydrogenase and gammaglutamyl transferase were normal. The patient did not want to undergo further tests, so the cyclophosphamide was stopped and she was given a packed cell transfusion and discharged. A muscle biopsy from the right deltoid did not show vasculitis. She died 10 months later, because of cardiogenic shock after an acute myocardial infarction; necropsy was not authorised.

\section{Discussion}

This patient's histopathological findings were those of a granulomatous vasculitis without renal, pulmonary, cutaneous, or neurological involvement. The pathological features of pulmonary granulomatous vasculitis are similar to those found in this case (fibrinoid necrosis, vascular and extravascular granulomas, giant cells), ${ }^{15}$ but the absence of lung, renal, cut- aneous, and neurological involvement, eosinophilia, asthma, or sinusitis rules out these possibilities, in agreement with newly revised diagnostic criteria. ${ }^{5}$ Likewise the presence of granulomas and giant cells (without eosinophilic or polymorphonuclear infiltrates), in addition to the absence of renal, cutaneous, neurological, or gastrointestinal involvement, would be very unusual in polyarteritis nodosa. ${ }^{15}$ There are several drugs which can cause hepatic granulomas ${ }^{6}$ or vasculitis ${ }^{78}$; however, in such cases there is commonly eosinophilia and cutaneous involvement in the form of leucocytoclastic vasculitis, with little evidence of fibrinoid necrosis and only rarely granulomatous vasculitis. ${ }^{278}$ Our patient was under treatment with tolbutamide and though this drug may produce hepatic granulomatosis or cholestatic hepatitis, ${ }^{9}$ we have not found any case of visceral vasculitis following its use. Two cases of granulomatous vasculitis with hepatic and visceral involvement have been described after treatment with glibenclamide, another sulphonylurea, and though one of these cases ${ }^{10}$ had some similarities with ours, both had the typical characteristics of drug related vasculitis (tissue eosinophilia, cutaneous involvement, and absence of fibrinoid necrosis and giant cells) ${ }^{78}$ which makes them very different from the histological findings in our patient.

The clinical and histological characteristics observed in our patient are similar to those of other patients described so far with idiopatic granulomatous angiitis ${ }^{34}$ (disseminated visceral granulomatous angiitis), that is, non-specific clinical manifestations, involvement of small and medium calibre arteries in several organs (liver, pancreas, heart, lymph glands), and the presence of necrotising granulomatous arteritis (figs 1 and 2), multinucleate giant cells (fig 2), and extravascular granulomas, with absence of eosinophilia (either in the tissues or in peripheral blood) or involvement of skin, central nervous system, and temporal arteries. Though fibrinoid necrosis is a relatively minor feature of this entity, nevertheless in one of the cases described it was prominent, ${ }^{4}$ as it was in our patient (fig 1). It was also striking that there was marked though non-specific muscular involvement in our patient, which was not present in the other cases described so far.

The patient was treated with $50 \mathrm{mg} /$ day of cyclophosphamide $(1 \mathrm{mg} / \mathrm{kg} /$ day $)$ for two and a half years and though, for reasons beyond our control, her treatment could only be reviewed at 3 and 30 months, she tolerated it well and there was striking clinical improvement and probably also histological improvement since in the second muscle biopsy lesions of vasculitis were not found.

Though, unfortunately, necropsy could not be performed, which would have completed the case description and made clear the cause of death, we believe that the findings reported here extend our knowledge about this rare disorder, and above all about its therapy, since this is the first time that satisfactory response to treatment with an immunosuppressive agent has been described. 
1 Cupps TR, Fauci AS. The vasculitides. In: Smith LH, ed. Major problems in internal medicine, vol 21. Philadelphia: WB Saunders, 1981: 26-49 and 72-87.

2 Gaffey CM, Chun B, Harvey JC Manz HJ. Phenytoininduced systemic granulomatous vasculitis. Arch Pathol induced systemic granulom

3 Lie JT. Disseminated visceral giant cell arteritis. Histopathologic description and differentiation from othe granulomatous vasculitides. Am f Clin Pathol 1978;69: 299-305.

4 Petersen OMF, Frankel SR. Idiopatic granulomatous vasculitis. In Churg A, Churg J, eds. Systemic vasculitides. New York: Igaku-Shoin, 1991;181-91.

5 Hunder GG, Arend WP, Bloch DA, Calabrese LH, Fauci AS, Fries JF, et al. The American College of Rheumatolog 1990 criteria for the classification of vasculitis. Arthritis Rheum 1990;33:1065-144.
6 Berk JE, Cohen M. Granulomas hepaticos. In: Berk JE, ed. Bockus: Gastroenterologia, 4th Spanish edition. Barcelona: Salvat, 1987:3475-90.

7 Mullick FG, McAllister HA, Wagner BM, Fenoglio JJ. Drug related vasculitis. Clinicopathologic correlations in 30 patients. Hum Pathol 1979;10:313-25.

8 Haber MM, Marboe CC, Fenoglio JJ. Vasculitis in drug reactions and serum sickness. In: Churg A, Churg J, eds. Systemic vasculitides. New York: Igaku-Shoin, 1991 : eds. System 13.

9 Bloodworth JMB, Hamwi GJ. Histopathologic lesions as sociated with sulfonylurea administration. Diabetes 1961 10:90-9.

10 Ingelmo $M$, Vivancos J, Bruguera M, Sierra J, Balcells A Angiitis por hipersensibilidad y hepatitis granulomatosa inducida por glibenclamida: a proposito de un caso. Med Clin (Barc) 1980;75:306-8.

\title{
Histological features of the thyroid gland in a patient with lithium induced thyrotoxicosis
}

\author{
Y Mizukami, T Michigishi, A Nonomura, S Nakamura, M Noguchi, E Takazakura
}

\section{Kanazawa \\ University Hospital, Kanazawa, Japan \\ Y Mizukami \\ A Nonomura \\ Department of Nuclear Medicine T Michigishi cytic infiltration. It is postulated that lithium might directly damage thyroid follicular cells and that subsequent re- lease of thyroglobulin into the circulation might be a cause of transient thyro- toxicosis. \\ (f Clin Pathol 1995;48:582-584)}

Department of Internal Medicine

S Nakamura

\section{Department}

of Surgery

M Noguchi

Kurobe Citizens Hospital, Kurobe, Japan: Department of Internal Medicine E Takazakura

Correspondence to: Dr Yuji Mizukami MD Pathology Section, Kanazawa University Hospital,

13-1 Takara-machi, Kanazawa 920, Japan.

Accepted for publication 13 October 1994

\begin{abstract}
A 26 year old woman with lithium induced thyrotoxicosis is reported. The thyrotoxicosis was associated with a nontender diffuse goitre and a low radioiodine uptake by the gland. The thyrotoxicosis was reversible and remitted on withdrawal of the drug. The histopathological alterations of the thyroid glad were characterised by extensive follicular cell disruption with no lympho-
\end{abstract}

Keywords: Thyrotoxicosis, lithium, thyroid histology.

Lithium is increasingly used for the treatment of manic depressive illness. Thyroid disturbances during lithium treatment have been noted. These commonly present as a goitre with or without hypothyroidism ${ }^{1-3}$; more rarely there is a goitre with hyperthyroidism. ${ }^{24-6}$ There have, however, been few reports describing the histological alterations of the thyroid gland during lithium treatment. ${ }^{23578}$

In the present report, we describe the histopathological features of the thyroid gland in a patient with lithium induced thyrotoxicosis which remitted on withdrawal of the drug.

\section{Case report}

A 26 year old woman was referred to us because of a two week history of sweating, palpitations, and anorexia. She had a three year history of manic depressive psychosis and had been taking lithium carbonate, $800 \mathrm{mg} /$ day, for the preceding two years. She had no history of thyroid disease and there was no family history of thyroid disorders. She was clinically euthyroid six months before this episode, and serum values at that time including a thyroxine (T4) of $90 \mathrm{nmol} / 1$ (normal 59-142), a free T4 of $19.6 \mathrm{pmol} / 1$ (normal 9.0-27.0), and a triiodothyronine (T3) of $1.7 \mathrm{nmol} / 1$ (normal 1.2 2.9). Physical examination revealed warm moist hands and fine finger tremor, but exophthalmos was not evident. The thyroid gland was diffusely enlarged and was non-tender. No nodules were palpable. The serum thyroid hormone concentrations were raised: free $\mathrm{T} 4$ $87.5 \mathrm{pmol} / 1$, T3 $3.5 \mathrm{nmol} / 1$, and free T3 $13.6 \mathrm{pmol} / 1$ (normal $3 \cdot 4-8 \cdot 2$ ). TSH was suppressed at $<2.0 \mathrm{mU} / 1$ (normal $<10 \cdot 0$ ). Radioactive iodine uptake was markedly reduced to only $1 \cdot 0 \%$ at 24 hours (normal $10-40 \%$ ). Serum antithyroglobulin and antimicrosome autoantibodies were negative. TSH binding inhibitor immunoglobulin (TBII) was also negative. These clinical and laboratory findings suggested a diagnosis of silent (painless) thyroiditis. Large needle biopsy (Silverman) of both lobes of the thyroid gland was performed. Lithium therapy was stopped and the patient was given propranolol for the control of thyrotoxic symptoms. The values of the serum thyroid hormones continued to rise for two 